\title{
SYNTHESIS AND DRUGLIKENESS ESTIMATION OF AMIDE DERIVATIVES OF 1-BENZYLTHEOBROMINE- 8-THIOGLYCOLIC ACID
}

\author{
Maya Georgieva, Javor Mitkov, Alexander Zlatkov \\ Department of Pharmaceutical chemistry, Faculty of Pharmacy, \\ Medical University of Sofia
}

\begin{abstract}
Five-stage synthetic scheme for obtaining of $\mathrm{N}$-substituted 1-benzyltheobromine-8-thioglicolacetamides was described. The intermediate compound 1-benzyl-8-bromotheobromine was synthesized using aliquat 336 as phase transfer catalyst in very good yield. Five amide derivatives of 1-benzyltheobromine-8-thioglicolyc acid were obtained in yields of 61 to $81 \%$. The structures of the studied compounds were established by FTIR, ${ }^{1} \mathrm{H}$ NMR spectral data. In order to estimate the drug-likeness of compounds $7 \mathrm{a}-\mathrm{e}$, a theoretical calculation of some molecular descriptors was made using two approaches: the Lipinski's Rule of Five limitations and the OSIRIS Property Explorer evaluation score. The comparison of the calculated results indicate that only one compound violates the Lipinski's Rule of Five parameters - 7c, which makes it unsuitable for further structural optimizations. On the other hand compound $7 \mathrm{e}$ shows the highest drug like properties with Fragment Based Druglikeness score of 2.58 and total Drug score of 0.43 which are better than the same scores of parent compound theobromine.
\end{abstract}

Keywords: 1-benzyltheobromine-8-thioglicolyc acid, 1-benzyltheobromine-8-thioglicolacetamides, druglikeness, Lipinski's Rule of Five

\section{INTRODUCTION}

Theobromine, formerly known as a bitter alkaloid of the cacao plant $(3,29)$, is a caffeine derivative and metabolite found primarily in chocolate. It may occur in the body as it is a product of the human metabolism of caffeine, which is metabolised in the liver into $10 \%$ theobromine, $4 \%$ theophylline, and $80 \%$ paraxanthine (27). In the liver, theobromine is metabolized into xanthine and subsequently into meth-

\footnotetext{
Address for correspondence:

Maya Georgieva, $\mathrm{PhD}$

Department of "Pharmaceutical chemistry"

Faculty of Pharmacy, Medical University, Sofia

2 "Dunav" str., 1000 Sofia, Bulgaria

Phone: +359 29236515

e-mail:georgm@mail.bg
}

Received: February 27, 2014

Accepted: April 3, 2014 yluric acid (10). Theobromine is highly fat soluble with peaking in the plasma 1-2 $\mathrm{h}$ after ingestion (21).

Like other methylated xanthine derivatives, theobromine is both a competitive nonselective phosphodiesterase inhibitor (13), which raises intracellular cAMP, activates PKA, inhibits TNF-alpha $(11,19)$ and leukotriene synthesis $(22)$, and reduces inflammation and innate immunity (22) and nonselective adenosine receptor antagonist (12). As a phosphodiesterase inhibitor, theobromine helps prevent the phosphodiesterase enzymes from converting the active cAMP to an inactive form (24).

As an adenosine receptor antagonist, theobromine appears to have equal affinity for $A_{1}$ compared to $A_{2 A}$ receptors, while caffeine shows a slightly lower affinity for $A_{1}$ receptors (25). Theobromine has one fifth the stimulant effect of caffeine, but with a longer half-life in the body (21). 
Maya Georgieva, Javor Mitkov, Alexander Zlatkov

As a phosphodiesterase inhibitor, theobromine inhibits phosphodiesterase (PDE) non-selectively and also shows adverse effects on the cardiovascular and central nervous systems $(1,5,8,15)$. It is of interest to investigate the structure-activity relationships of alkylxanthines. During this investigation has been found that the alkyl substitution at N1 leads to increased selectivity to PDE4 inhibition. In addition, introduction of a benzyl group at the N1 position results in a potent and selective PDE4 inhibitor, with the most potent PDE4 inhibitory activity among xanthine derivatives known to be PDE4 inhibitors (26).

These results determined the purpose of our work to obtain amide derivatives of 1-benzyltheobromine-8-thioglycolic acid and to determine their drug-like properties as preliminary information for their further application as potential PDE inhibitors.

\section{MATERIAL AND METHODS}

\section{Apparatuses and devices}

The used chromatographic system for TLC control and purity elucidation is based on an alimunium sheets Silica gel F254 (Merck, Darmstadt, Germany), using the following mobile phases: Phase 1: $25 \%$ $\mathrm{NH}_{4} \mathrm{OH} /$ Acetone $/ \mathrm{CHCl}_{3} / \mathrm{CH}_{3} \mathrm{CH}_{2} \mathrm{OH}(1 / 3 / 3 / 4)$ and Phase 2: $\mathrm{H}_{2} \mathrm{O} / \mathrm{n}$-butanol/ $\mathrm{CH}_{3} \mathrm{COOH}(5 / 4 / 1)$, with detection at UV $254 \mathrm{~nm}$. Yields were calculated for purified products. The IR spectra $400-4000 \mathrm{~cm}^{-1}$ were recorded on a Shimadzu FT-IR Spectrometer in $\mathrm{KBr}$ pellets. The ${ }^{1} \mathrm{H}-\mathrm{NMR}$ spectra were registered at 100 $\mathrm{MHz}$ on spectrometer Bruker 100 (Faenlanden, Switzerland) as $\delta$ (ppm) relative to TMS as internal standard and the coupling constants $(J)$ are expressed in Hertz $(\mathrm{Hz})$. All $\mathrm{NH}$ protons were $\mathrm{D}_{2} \mathrm{O}$ exchangeable. All names were generated by using ACD/Name Version 2.51 (9).

The starting materials were of commercially available research - grade chemicals. (Merck, Darmstadt, Germany). Commercial aliquat 336 was used as catalysts.

\section{Synthesis of 8-bromotheobromine (2)}

The bromination of theobromine was carried out in a four-neck round bottom flask (total volume $1000 \mathrm{ml}$ ) placed in a heating mantle with a mechanical stirrer and temperature controller. The centre neck was fitted with mechanical stirrer whose speed was maintained at $700 \mathrm{rpm}$. A thermometer for temperature control and a Liebig condenser for reflux were inserted into two of the side necks. The other side neck allowed sampling of the reaction mixture. A $0.1 \mathrm{~mol}$ of theobromine were dissolved in $200 \mathrm{ml}$ acetic acid. $29 \mathrm{ml}$ of $62 \% \mathrm{HBr}$ were added to the solution. The temperature was raised up to $80^{\circ}-85^{\circ} \mathrm{C}$. After complete homogenization of the reaction mixture $25 \mathrm{ml} \mathrm{30 \%}$ hydrogen peroxide were added dropwise. The reaction mixture was left under the same conditions for 4 hours, then cooled to room temperature and decolourized with sodium sulphite. The colorless solution was poured into $400 \mathrm{ml}$ ice water and kept for 12 hours at $4^{\circ} \mathrm{C}$. The separated precipitate of 8-bromotheobromine was filtered under reduced pressure and recrystallised from ethanol. Yield $23.2 \mathrm{~g}(85 \%)$, m.p. - above $300^{\circ} \mathrm{C}$. The structure of the compound was confirmed by IR spectral analysis.

Synthesis of 1-benzyl-8-bromotheobromine (3)

In a round bottom flask $0.04 \mathrm{~mol}$ of 8 -bromotheobromine and $0.06 \mathrm{~mol}$ of finely powdered $\mathrm{KOH}$ were suspended in $50 \mathrm{ml}$ benzyl chloride. A half milliliter of the catalyst aliquot 336 was added and the temperature was raised under a glycerin bath up to $150^{\circ} \mathrm{C}$ for one hour. The reaction was controlled by TLC and stopped after exhaustion of the starting compounds. After cooling a volumetric precipitate of 1-benzyl-8-bromotheobromine was formed. The obtained crystals were filtered and washed with petroleum ether. After drying out the crystals were processed with $50 \mathrm{ml}$ of water and filtered again. The filtrate was evaporated and the benzyl chloride residue was regenerated. The yield after purification was $98 \%$, m.p. $-185-187^{\circ} \mathrm{C}$. The structure of the compound was confirmed by IR spectral analysis.

Synthesis of 1-benzyltheobromine-8-thioglicolic acid (4)

The reaction was carried out in reactor of 500 $\mathrm{ml}$ capacity which was equipped with mechanical stirrer (speed was maintained at $700 \mathrm{rpm}$ ) and a reflux condenser was placed on top of the reactor in order to prevent the escape of volatile compounds. The reaction mixture is water: ethanol $=40: 60.0 .06 \mathrm{~mol}$ sodium hydroxide was preliminary solved in the water phase. Afterwards $0.03 \mathrm{~mol}$ of thioglicolic acid were added. The ethanol and the $0.029 \mathrm{~mol}$ of 1-benzyl-8-bromotheobromine were added and the re- 
action mixture was heated under reflux for 1 and a half hour. The reaction mixture is filtered when hot and acidified with previously prepared solution of 1 part acetic acid and 4 parts water, with $\mathrm{pH}$ about 2 . A white precipitate was obtained, which was filtered and dissolved in 5\% sodium hydrogen carbonate. The insoluble sodium salt of the unreacted 1-benzyl-8-bromotheobromine was formed. The mixture was filtered and the filtrate was acidified with $\mathrm{c} . \mathrm{HCl}$ to $\mathrm{pH}$ about 3. The separated precipitate was filtered under vacuum and dried. Yield -81\%, m.p. - 193 $-194^{\circ} \mathrm{C}$. The structure of the compound was confirmed by IR spectral analysis and its purity was elucidated by TLC.

Synthesis of methyl ester of 1-benzyltheobromine-8-thioglicolic acid (5)

Esterification of 1-benzyltheobromine-8-thioglicolic acid was performed according to the classical esterification (23) by interaction of the corresponding acid and alcohol in presence of sulfuric acid. The reaction was carried out in a round bottom flask in excess of anhydrous methanol $(300 \mathrm{ml})$. The flask was placed in a cooling bath and $30 \mathrm{ml}$ of $\mathrm{H}_{2} \mathrm{SO}_{4}$ were added in aliquots. After its full addition $17 \mathrm{~g}$ of 1-benzyltheobromine-8-thioglicolic acid were added and the mixture was boiled under reflux for 4 hours. The process was monitored by TLC until exhaustion of the initial thioglicolic acid. After the end of the reaction the mixture was filtered and a triple amount of water was added to the filtrate. The mixture was kept for 24 hours at $12^{\circ} \mathrm{C}$ until formation of a volumetric precipitate, which was filtered and purified by re-crystallization from ethanol. Yield -86.1\%, m.p. $-143-144^{\circ} \mathrm{C}$. The structure of the compound was confirmed by IR spectral analysis and its purity was elucidated by TLC.

General procedure for the synthesis of amides of 1-benzyltheobromine-8-thioglicolic acid (7a-e)

In a conical flask 0.005 mol of methyl ester of 1-benzyltheobromine-8-thioglicolic acid and 0.01 mol of the corresponding amine (6a-e) was mixed and placed in glycerin bath at $115^{\circ}-130^{\circ} \mathrm{C}$ respectively. The process was monitored by TLC until exhaustion of the initial compounds. The obtained crystals were purified accordingly by re-crystallization from ethanol and/or ether.
The IUPAC names of the newly synthesized compounds together with the interpretation of their IR and ${ }^{1} \mathrm{H}$ NMR spectra are presented below; the chemical structures are presented in Fig. 3, the relevant melting points and the individual yields are presented in Table 1.

2-(1-benzyl-3,7-dimethyl-2,6-dioxo-2,3,6,7-tetrahydro-1H-purin-8-ylthio)-N-cyclohexylacetamide (7a): IR (KBr): v 1725, 1705, 1685, 1605, 1558; ${ }^{1} \mathrm{H}$ NMR (100 MHz, DMSO-d $) \delta$, ppm: 9.40 (s, 1H, NH), 7.24$7.36\left(\mathrm{~m}, 5 \mathrm{H}, \mathrm{C}_{6} \mathrm{H}_{5}\right), 4.80$ (s, 2H, N1- $\left.\mathrm{CH}_{2}\right), 3.48$ (s, 3H, N3- $\left.\mathrm{CH}_{3}\right), 3.70$ (s, 2H, S-CH $\mathrm{CH}_{2}, 3.82$ (s, 3H, N7-CH ${ }_{3}$, 1.36-3.85 (m, 11H, $\left.\mathrm{C}_{6} \mathrm{H}_{11}\right)$.

2-(1-benzyl-3,7-dimethyl-2,6-dioxo-2,3,6,7-tetrahydro-1H-purin-8-ylthio)-N-cyclohexyl-N-ethyl acetamide (7b): IR (KBr): v 1720, 1702, 1680, 1552; ${ }^{1} \mathrm{H}$ NMR (100 MHz, DMSO-d $\left.)_{6}\right) \delta$, ppm: 7.24-7.36 (m, $\left.5 \mathrm{H}, \mathrm{C}_{6} \mathrm{H}_{5}\right), 4.80\left(\mathrm{~s}, 2 \mathrm{H}, \mathrm{N} 1-\mathrm{CH}_{2}\right), 3.45$ (s, 3H, N3$\left.\mathrm{CH}_{3}\right), 3.70\left(\mathrm{~s}, 2 \mathrm{H}, \mathrm{S}-\mathrm{CH}_{2}\right), 3.80\left(\mathrm{~s}, 3 \mathrm{H}, \mathrm{N} 7-\mathrm{CH}_{3}\right), 1.40-$ $3.80\left(\mathrm{~m}, 22 \mathrm{H}, 2 \mathrm{xC}_{6} \mathrm{H}_{11}\right)$.

2-(1-benzyl-3,7-dimethyl-2,6-dioxo-2,3,6,7-tetrahydro-1H-purin-8-ylthio)-N,N-dicyclohexylacet amide (7c): IR (KBr): v 1715, 1702, 1684, 1554; ${ }^{1} \mathrm{H}$ NMR (100 MHz, DMSO-d $) \delta$, ppm: 7.24-7.36 (m, $5 \mathrm{H}, \mathrm{C}_{6} \mathrm{H}_{5}$ ), 4.80 (s, 2H, N1- $\mathrm{CH}_{2}$ ), 3.46 (s, 3H, N3$\left.\mathrm{CH}_{3}\right), 3.70$ (s, 2H, S-CH $), 3.80\left(\mathrm{~s}, 3 \mathrm{H}, \mathrm{N} 7-\mathrm{CH}_{3}\right), 3.26$ (m, $\left.2 \mathrm{H}, \mathrm{N}-\underline{\mathrm{CH}}_{2} \mathrm{CH}_{3}\right), 1.36-3.88\left(\mathrm{~m}, 11 \mathrm{H}, \mathrm{C}_{6} \mathrm{H}_{11}\right), 1.22$ (t, 3H, N-CH $2 \underline{\mathrm{CH}}_{3}$ ).

2-(1-benzyl-3,7-dimethyl-2,6-dioxo-2,3,6,7-tetrahydro-1H-purin-8-ylthio)-N-cyclohexyl-N-methyl acetamide (7d): IR (KBr): v 1716, 1702, 1680, 1555; ${ }^{1} \mathrm{H}$ NMR (100 MHz, DMSO-d $)$, ppm: 7.24-7.36 (m, $\left.5 \mathrm{H}, \mathrm{C}_{6} \mathrm{H}_{5}\right), 4.80\left(\mathrm{~s}, 2 \mathrm{H}, \mathrm{N} 1-\mathrm{CH}_{2}\right), 3.45$ (s, 3H, N3$\left.\mathrm{CH}_{3}\right), 3.70$ (s, 2H, S-CH $), 3.80\left(\mathrm{~s}, 3 \mathrm{H}, \mathrm{N} 7-\mathrm{CH}_{3}\right), 3.26$ (s, $\left.2 \mathrm{H}, \mathrm{N}-\underline{\mathrm{CH}}_{2} \mathrm{CH}_{3}\right), 1.38-3.80\left(\mathrm{~m}, 11 \mathrm{H}, \mathrm{C}_{6} \mathrm{H}_{11}\right), 3.72$ (s, 3H, N-CH $\mathrm{H}_{3}$.

2-(1-benzyl-3,7-dimethyl-2,6-dioxo-2,3,6,7-tetrahydro-1H-purin-8-ylthio)-N-((tetrahydrofuran2-yl)methyl)acetamide (7e): IR (KBr): v 1720, 1701, 1684, 1595, 1552; ${ }^{1} \mathrm{H}$ NMR (100 MHz, DMSO-d $) \delta$, ppm: 9.40 (s, 1H, NH), 7.24-7.36 (m, 5H, $\left.\mathrm{C}_{6} \mathrm{H}_{5}\right), 4.80$ (s, 2H, N1- $\mathrm{CH}_{2}$ ), 3.40 (s, 3H, N3- $\mathrm{CH}_{3}$ ), 3.70 (s, $2 \mathrm{H}$, 
S-CH ${ }_{2}$ ), 3.81 (s, 3H, N7-CH $\left.{ }_{3}\right), 3.13\left(\mathrm{~s}, 2 \mathrm{H}, \mathrm{NH}-\underline{\mathrm{CH}}_{2}\right)$, 1.86-4.23 (m, 7H, furan).

\section{RESULTS AND DISCUSSION}

The synthesis of amide derivatives of 1-benzyltheobromine-8-thioglicolic acid consists of brominating of theobromine (1) to obtain 8-bromotheobromine (2). Its further interaction with benzyl chloride resulted in synthesis of 1-benzyl-8-bromotheobromine (3). The next stage is the formation of the corresponding 1-benzyltheobromine-8-thioglicolic acid (4) by interaction of (3) with thioglycolic acid. The necessary for the aminolysis ester derivative (5) was obtained by esterification. The targeted structures were synthesized by classical aminolysis. The total synthetic scheme for the preparation of the initial methyl ester of 1-benzyltheobromine-8-thioglicolic acid is presented on Fig. 1. thesis was performed under phase-transfer catalysis conditions, whereat aliquat 336 was used as catalyst. The corresponding reaction is presented on Fig. 2.

Based on previous experiments improving the reaction conditions (20) we led the reaction in water/ ethanol media, in the presence of sodium hydroxide. At these conditions no side reaction was observed and the reaction time was shortened up to 1 and a half hour with yield of $81 \%$. The next stage is formation of the corresponding 1-benzyltheobromine8-thioglicolic acid (4) by interaction of (3) with thioglycolic acid. The necessary for the aminolysis, ester derivative (5), was obtained by classical esterification (23).

The targeted amide derivatives were synthesized by interaction of the corresponding amine and the methyl ester of 1-benzyltheobromine-8-thiogli-

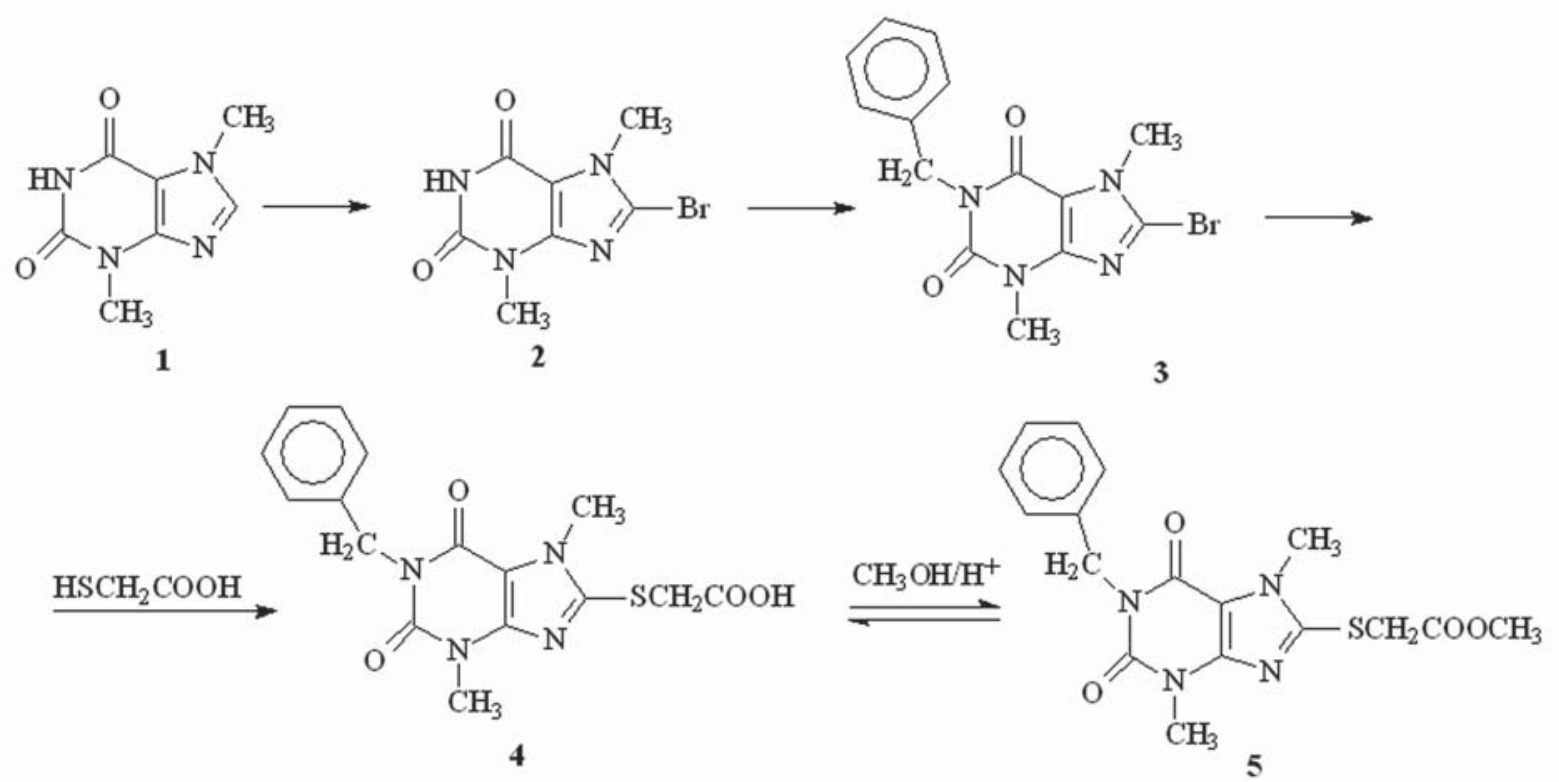

Fig. 1. General scheme of synthesis of methyl ester of 1-benzyltheobromine-8-thioglicolic acid

The synthesis of 8-bromotheobromine (2) was carried out via oxidative bromination of theobromine (1) according to the literary method (14), based on application of $\mathrm{HBr}$ and $\mathrm{H}_{2} \mathrm{O}_{2}$ in glacial acetic acid. Under these conditions the reaction due 4 hours and the corresponding yield of re-crystallized 8-bromotheobromine was $80-85 \%$.

The next stage of our synthetic sequence is obtaining 1-benzyl-8-bromotheobromine (3). The syn- colic acid, according to Fig. 3 .

The aminolysis of the compounds was performed in melt, with 2:1 correlation of the reactants for the selected amine. For all the synthesis the reaction mixture was heated in glycerin bath until the methyl ester of 1-benzyltheobromine-8-thioglicolic acid was melted, which formed melt with the applied amine, and this temperature is maintained until the 
<smiles>Cn1c(Br)nc2c1c(=O)[nH]c(=O)n2C</smiles>

2

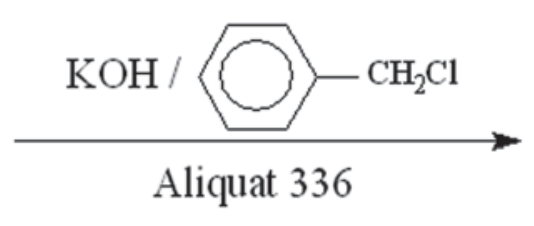<smiles>Cn1c(Br)nc2c1c(=O)n(Cc1ccccc1)c(=O)n2C</smiles>

Fig. 2. Synthesis of 1-benzyl-8-bromotheobromine<smiles>COC(=O)CSc1nc2c(c(=O)n(Cc3ccccc3)c(=O)n2C)n1C</smiles><smiles>[R]CC1CCCCC1</smiles><smiles>[R]C(=[V])CCC1CCCCC1</smiles><smiles>[R][R]#CC1CCCCC1</smiles><smiles>[R12]C(=O)CSc1nc2c(c(=O)n(Cc3ccccc3)c(=O)n2C)n1C</smiles>

Fig. 3. General scheme for synthesis of the targeted amide derivatives of 1-benzyltheobromine-8-thioglicolic acid

end of the reaction. The reaction times are between $20 \mathrm{~min}$ to one hour, the temperature vary from 110 to $130^{\circ} \mathrm{C}$ and the yields are in range of 61 to $81,2 \%$.

Using the above described methods five amide derivatives of 1-benzyltheobromine-8-thioglicolic acid were synthesized. The reaction conditions and the corresponding reaction time and yield for each of the targeted products are given in Table 1.

It is clearly seen in Table 1 that target products 7a-e are obtained with good yields and purity, whereas $7 \mathbf{a}$ is obtained with highest yield. The structure of the newly synthesized compounds was proven by elemental analysis, IR and ${ }^{1} \mathrm{H}-\mathrm{NMR}$ spectroscopy.

The obtained structures are white crystalline powders, soluble in organic solvents (chloroform, benzene, dimethylformamide) and practically insoluble in water. The obtained amides are stable to hydrolysis under acidic or alkali conditions, close to physiological $\mathrm{pH}$ and temperatures about $40^{\circ} \mathrm{C}$. Under these conditions no hydrolysis is observed for a period of more than 20 hours.

The FT-IR spectra of the studied N-substituted 1-benzyltheobromine-8-thioglycolacetamides 7a-e in the region of the $4000-400 \mathrm{~cm}^{-1}$ exhibit several characteristic bands. The two strong bands at about 1680 to $1702 \mathrm{~cm}^{-1}$ are ascribable to the streching vibration of two carbonyl groups in the xanthine ring. The vibrational band recorded at $1716-1725 \mathrm{~cm}^{-1}$ belongs to the carbonyl in the amide moiety in the side chain (amide I), while the band at 1595 - 1605 
Maya Georgieva, Javor Mitkov, Alexander Zlatkov

Table 1. Reaction conditions and the corresponding reaction time and yield and melting points for the synthesis of each
of the targeted products

$\mathrm{cm}^{-1}$ in the spectra of $7 \mathbf{a}, \mathbf{e}$ corresponds to streching vibration N-H from the same residue (amide II). This band do not present in the spectra of the other compounds since they are tertiary amides. The band at about $1550 \mathrm{~cm}^{-1}$ belongs to the streching vibration of $\mathrm{C}=\mathrm{C}$ bonds in xanthine ring.

More detailed information about the structure of compounds $7 \mathbf{a}-\mathbf{e}$ was provided by the ${ }^{1} \mathrm{H}$ NMR spectra. Thus, the strong singlets at $3.45 \div 3.48$ and $3.80 \div 3.82 \mathrm{ppm}$ in the spectrum of the studied compounds correspond to $\mathrm{N}$-methyl protons at position 3 and 7. The signal of the $\mathrm{N}$-methylene group from 1-benzyltheobromine-8-thioglycolic acid at position 8 appears at $3.70 \mathrm{ppm}$ as broad singlet. The signals of methylene protons from the benzyl side chain at position 1 form strong singlet at $4.80 \mathrm{ppm}$. The signals of the aromatic protons from benzyl side chain at position 1 in the spectra of $7 \mathbf{a}-\mathbf{e}$ correspond to complicated multiplets between 7.24 and 7.36 ppm, but the integral curves correspond to the exact number of the protons. The signals of methylene protons from the cyclohexyl residue of 7a-d form broad multiplet between 1.68 and $1.39 \mathrm{ppm}$. The methyne proton from the cyclohexyl residue forms a multiplet with weak intensity between 3.85 and $3.80 \mathrm{ppm}$. In the spectrum of $\mathbf{7 d}$ there is a strong singlet at 3.75 ppm that corresponds to $\mathrm{N}$-methyl protons in the side chain. The ethyl group in the spectrum of $7 \mathbf{b}$ appears as multiplet at $3.26 \mathrm{ppm}$ and strong triplet at $1.22 \mathrm{ppm}$. There are some differences between spectrum of $7 \mathbf{e}$ and these of $\mathbf{7 a - d}$ where protons of tetrahydrofurylmethyl residue form broad complex multiplets between 1.86 and $4.23 \mathrm{ppm}$. The values of the chemical shifts of the protons registered by ${ }^{1} \mathrm{H}$ NMR spectra were compared with simulated values $(2,4$, $6,7)$. We observed only small deviations of computed from experimental values, due to an impossibility to render an account of influence of the solvent. Regardless, the simulated ${ }^{1} \mathrm{H}$ NMR spectra are in good correlation with the experimental ones.

\section{Druglikeness prediction}

There are many approaches that assess a compound's "druglikeness", partially based on topological descriptors, fingerprints of MDL structure keys or other properties. In addition the biological activity is also usually a function of the complex influence of a number of molecular descriptors. In some cases, an underlayment of a certain parameter is possible, whereas the hydrophobicity of the compounds, usually expressed as $\log \mathrm{P}$, appears to be a key parameter for determination of compounds druglikeness.

In the present work we have applied two approaches in an attempt to evaluate the drug-like properties of the newly synthesized by us amide derivatives of 1-benzyltheobromine-8-thioglicolic acid: the Lipinski's Rule of Five limitations and the OSIRIS Property Explorer evaluation score.

Determination of Lipinski's Rule of Five parameters

Lipinski's rule of five also known as the Rule of five (RO5) is a rule of thumb to evaluate druglikeness or determine if a chemical compound with a certain pharmacological or biological activity has properties that would make it a likely orally active drug in humans. The rule was formulated by Christopher A. Lipinski in 1997, based on the observation that most medication drugs are relatively small and lipophilic molecules $(16,17)$. The rule describes molecular properties important for a drug's pharmacokinetics in the human body, including their absorption, distribution, metabolism, and excretion ("ADME"). However, the rule does not predict if a compound is pharmacologically active. Candidate drugs that confirm to the RO5 tend to have lower attrition rates 
Synthesis and druglikeness estimation of amide derivatives of 1-benzyltheobromine-8-thioglycolic acid

Table 2. Structure and some molecular parameters of the newly synthesized amide derivatives of 1-benzyltheobromine8-thioglicolic acid

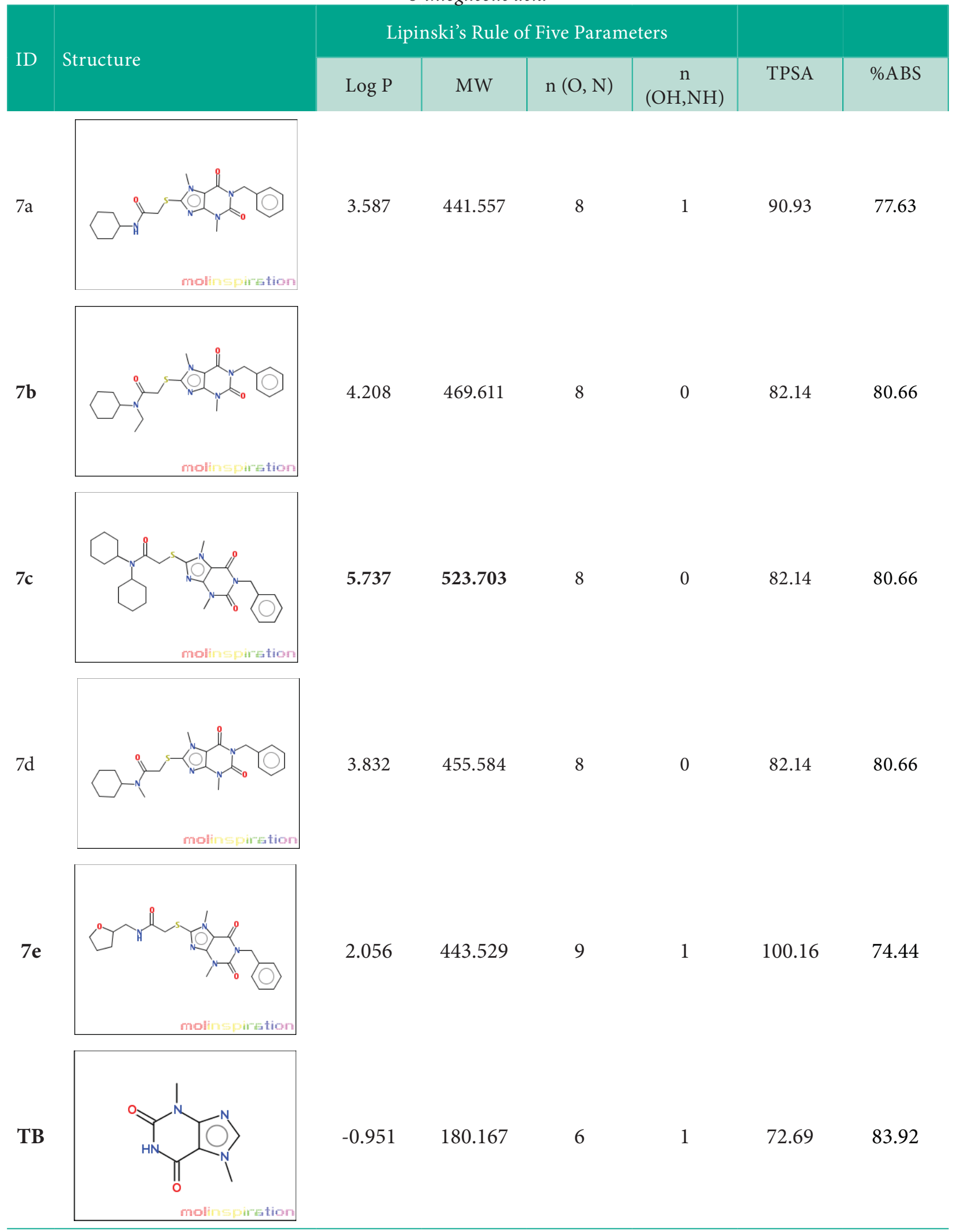


Maya Georgieva, Javor Mitkov, Alexander Zlatkov

during clinical trials and hence have an increased chance of reaching the market $(17,18)$. Lipinski's rule states that, in general, an orally active drug has no more than one violation of the following criteria: 1) no more than 5 hydrogen bond donors (nitrogen or oxygen atoms with one or more hydrogen atoms); 2) not more than 10 hydrogen bond acceptors (nitrogen or oxygen atoms); 3) a molecular mass less than 500 daltons and 4) an octanol-water partition coefficient $\log P$ not greater than 5 .

In the present work, the Lipinski's parameters were calculated with the help of the web based server Molinspiration Cheminformatics (31). This software offers broad range of cheminformatics software tools supporting molecule manipulation and processing, including SMILES and SDfile conversion, normalization of molecules, generation of tautomers, molecule fragmentation, calculation of various molecular properties needed in QSAR, molecular modeling and drug design, high quality molecule depiction, molecular database tools supporting substructure and similarity searches (31).

Using this software we calculated the values of the Lipinski's Rule of Five parameters and the obtained results are presented in Table 2.

From the performed calculation is obvious, that only one structure violates the Lipinski's Rule of Five parameters $-\mathbf{7 c}$, which makes it unsuitable for further structural optimizations.

In addition we determined the extension of absorption, expressed by the percentage of absorption. The absorption percent was calculated (30) using the expression: \%ABS $=109-0.345$ PSA.

Evaluation of drug-like properties of the new synthesized compounds, using the OSIRIS Property Explorer tool.

The OSIRIS Property Explorer used in this publication for druglikeness prediction tool is an integral part of Actelion's inhouse substance registration system (28). The prediction process relies on a precomputed set of structural fragment that gives preliminary information on a number of drug-relevant properties, like druglikeness and/or toxicity alerts.

\section{Evaluation of druglikeness}

The synthesized by us new amide derivatives of 1-benzyltheobromine-8-thioglicolic acid were evaluated for druglikeness, using the web based serv- er OSIRIS Property Explorer (32). The corresponding molecule's druglikeness was assessed by two parameters: Fragment Based Druglikeness and Drug Score.

\section{Fragment Based Druglikeness}

This parameter is calculated with the following equation summing up score values of those fragments that are present in the molecule under investigation:

$$
d=\frac{\sum v_{i}}{\sqrt{n}}
$$

A positive value states that the analyzed molecule contains predominatly fragments which are frequently present in commercial drugs (33).

\section{Drug Score}

The drug score combines druglikeness, cLogP, $\log S$, molecular weight and toxicity risks in one handy value that may be used to judge the compound's overall potential to qualify for a drug. This value is calculated by multiplying contributions of the individual properties with the first equation:

$$
d s=\Pi\left(\frac{1}{2}+\frac{1}{2} S_{i}\right) \cdot \Pi t_{i}
$$

where: $\mathrm{ds}$ is the drug score. $\mathrm{s}_{\mathrm{i}}$ are the contributions calculated directly from of cLogP, logS, molweight and druglikeness $\left(\mathrm{p}_{\mathrm{i}}\right)$ via the second equation which describes a spline curve.

$$
S_{i}=\frac{1}{1+e^{a p_{i}+b}}
$$

Parameters $a$ and $b$ are $(1,-5),(1,5),(0.012,-6)$ and $(1,0)$ for cLogP, $\operatorname{logS}$, molweight and druglikeness, respectively. $t_{i}$ are the contributions taken from the 4 toxicity risk types. The $t_{i}$ values are 1.0, 0.8 and 0.6 for no risk, medium risk and high risk, respectively (34).

The corresponding values of the computational analysis are presented in Table 3.

From the performed evaluation was established, that compound 7e shows a highest drug like properties with Fragment Based Druglikeness score of 2.58 and total Drug score of 0.43 .

\section{Evaluation of toxicity risks}

The fragment lists, necessary for evaluation of toxicity risks, were created by rigorously shreddering all compounds of the RTECS database known to be active in a certain toxicity class (e.g. mutagen- 
Synthesis and druglikeness estimation of amide derivatives of 1-benzyltheobromine-8-thioglycolic acid

Table 3. Druglikeness and drug score values for newly synthesized compounds

\begin{tabular}{|l|c|c|}
\hline Compound & $\begin{array}{c}\text { Druglikeness } \\
\text { score }\end{array}$ & Drug score \\
\hline 7a & -1.05 & 0.24 \\
$\mathbf{7 b}$ & -0.68 & 0.24 \\
$\mathbf{7 c}$ & -6.11 & 0.12 \\
$\mathbf{7 d}$ & -1.16 & 0.20 \\
$\mathbf{7 e}$ & $\mathbf{2 . 5 8}$ & $\mathbf{0 . 4 3}$ \\
Theobromine & 1.65 & 0.19 \\
\hline
\end{tabular}

icity). During the shredding any molecule was first cut at every rotatable bonds leading to a set of core fragments. These in turn were used to reconstruct all possible bigger fragments being a substructure of the original molecule. Afterwards, a substructure search process determined the occurrence frequency of any fragment (core and constructed fragments) within all compounds of that toxicity class (35).

Due to the high structural similarity in the evaluated group of compounds it was determined, that for all the compounds a high risk of tumorigenic toxicity may be predicted, which is result from the presence of the corresponding group in all the target structures:<smiles>CNC(=O)N(C)C</smiles>

In addition the presence of the presented below structural fragment<smiles>CNC(=O)CS</smiles>

may be a reason for the expected performance from structure $\mathbf{7 d}$ of medium risk of mutagenicity.

\section{CONCLUSION}

The synthesis of 1-benzyltheobromine-8-thioglycolacetamides consists of bromination of theobromine to obtain the corresponding 8-bromotheobromine, its benzylation at position 1 in the presence of aliquat 366 as phase transfer catalist and further interaction with thioglycolic acid with subsequent esterification with methanol. The corresponding amide derivatives are further obtained by aminolysis of the methyl ester with the desired amine. The newly synthesized 7a-e are crystal compounds with white to very pale-yellow colour, soluble in DMF, sparingly soluble in alcohol and insoluble in water. The structures of the studied compounds were established by FTIR, ${ }^{1} \mathrm{H}$ NMR spectral data. In order to estimate the drug-likeness of compounds 7a-e, a theoretical calculation of some molecular descriptors was made using two approaches: the Lipinski's Rule of Five and the OSIRIS Property Explorer evaluation score. The comparison of the calculated results indicate that only one compound violates the Lipinski's Rule of Five parameters $-\mathbf{7 c}$, which makes is unsuitable for further structural optimizations. On the other hand compound $7 \mathrm{e}$ shows a highest drug like properties with Fragment Based Druglikeness score of 2.58 and total Drug score of 0.43 which are better than the same scores of parent compound theobromine. For all of the compounds a good oral bioavailability manifestation may be expected. The possible pharmacological effects and clarification of their potential as prodrugs will be further estimated.

\section{REFERENCES}

1. Amer MS, Kreighbaum WE. Cyclic nucleotide phosphodiesterases: properties, activators, inhibitors, structure activity relationship \& possible role in drug development. J Pharm Sci. 1975;64:1-37.

2. Aires-de-Sousa M, Hemmer J. Gasteiger. Prediction of $1 \mathrm{H}$ NMR Chemical Shifts Using Neural Networks. Analytical Chemistry. 2002;74(1).

3. Baer DM, Pinkston EM. Environment and Behavior. Westview Press; 1997.

4. Banfi D, Patiny L. Www.nmrdb.org: Resurrecting and processing NMR spectra on-line. Chimia. 2008;62(4):280-1.

5. Belardinelli L, Belloni FL, Rubio R, Berne RM. Atrioventricular conduction disturbances during hypoxia: possible role of adenosine in rabbit and guinea pig heart. Circ Res. 1980;47:684-91.

6. Binev Y, Aires-de-Sousa J. Structure-Based Predictions of $1 \mathrm{H}$ NMR Chemical Shifts Using FeedForward Neural Networks. J Chem Inf Comp Sci. 2004;44(3):940-5.

7. Binev Y, Corvo M, Aires-de-Sousa J. The Impact of Available Experimental Data on the Prediction of 1H NMR Chemical Shifts by Neural Networks. J Chem Inf Comp Sci. 2004;44(3):946-9. 
Maya Georgieva, Javor Mitkov, Alexander Zlatkov

8. Blinks JR, Olson CB, Jewell BR, Braveny P. Influence of caffeine and other methylxanthines on mechanical properties of isolated mammalian heart muscle. Circ Res. 1972;30:367-92.

9. Chem Draw Ultra, Version 9.0, CambridgeSoft.

10. Cornish HH, Christman AA. A Study of the Metabolism of Theobromine, Theophylline, and Caffeine in Man. J Biol Chem. 1957 Sep;228(1):315-23.

11. Deree J, Martins JO, Melbostad H, Loomis WH, Coimbra R. Insights into the regulation of TNF-alpha production in human mononuclear cells: the effects of non-specific phosphodiesterase inhibition. Clinics (São Paulo). 2008;63(3):321-8.

12. Daly JW, Jacobson KA, Ukena D. Adenosine receptors: development of selective agonists and antagonists. Prog Clin Biol Res. 1987;230(1):41-63.

13. Essayan DM. Cyclic nucleotide phosphodiesterases. J Allergy Clin Immunol. 2001;108(5):671-80.

14. Gagausov J, Peikov P, Davkov D, Sharankov K. Synthesis of 8-bromo-methylxanthines. Pharmacia. 1987;37(6):8-10.

15. Jahnel U, Nawrath H. Characterisation of adenosine receptors in guinea-pig left atria. Br J Pharmacol. 1989;97:1182-90.

16. Lipinski CA, Lombardo F, Dominy BW, Feeney PJ. Experimental and computational approaches to estimate solubility and permeability in drug discovery and development settings. Adv Drug Deliv Rev. 2001;46(1-3):3-26.

17. Lipinski CA. Lead- and drug-like compounds: the rule-of-five revolution. Drug Discovery Today: Technologies. 2004;1(4):337-41.

18. Leeson PD, Springthorpe B. The influence of druglike concepts on decision-making in medicinal chemistry. Nat Rev Drug Discov. 2007;6(11):881-90.

19. Marques LJ, Zheng L, Poulakis N, Guzman J, Costabel U (February). Pentoxifylline inhibits TNF-alpha production from human alveolar macrophages. Am J Respir Crit Care Med. 1999;159(2):508-11.

20. Mitkov J, Georgieva M, Zlatkov Al. Development of an optimized synthetic approach for synthesis of caffeine-8-thioglycolic acid and its ester derivatives. Pharmacia. 2012;59(1-4):17-23.

21. Mumford GK, Benowitz NL, Evans SM, Kaminski BJ, Preston KL, Sannerud CA, et al. Absorption rate of methylxanthines following capsules, cola and chocolate. Eur J Clin Pharmacol. 1996;51:319-25.
22. Peters-Golden M, Canetti C, Mancuso P, Coffey MJ. Leukotrienes: underappreciated mediators of innate immune responses. J Immunol. 2005;174(2):589-94.

23. Piimenko BA, Romanenko NI, Fedulova IV, Orestenko LP, Chervinskyi AY, Garmash SN. Synthesis and biological properties of (3-methyl-7-alylxanthinyl-8) thioglycolic acids derivatives. Chimicopharmacevticheskih journal. 1986;11:1322-4.

24. Phosphodiesterase. On-Line Medical Dictionary. [Cited 2007 Feb 23].

25. Svenningsson P, Nomikos GG, Fredholm BB. The stimulatory action and the development of tolerance to caffeine is associated with alterations in gene expression in specific brain regions. J Neurosci. 1993;19:4011-22.

26. Suzuki H, Sawanishi H, Nomura M, Shimada T, Miyamoto K. Effects of 1-Benzylxanthines on Cyclic AMP Phosphodiesterase 4 Isoenzyme. Biol Pharm Bull. 2006;29(1):131-4.

27. The Pharmacogenetics and Pharmacogenomics Knowledge Base. [Cited 2011 Jan 8].

28. Thomas Sander, Actelion Pharmaceuticals Ltd., Gewerbestrasse 16, 4123 Allschwil, Switzerland.

29. William MM. Dictionary of Bio-Chemistry and Related Subjects. New York: Philosophical Library; 1943; p. 311, 530, 573.

30. Zhao YH, Abraham MH, Lee J, Hersey A, Luscombe CN, Beck G, et al. Rate-limited steps of human oral absorption and QSAR studies. Pharm Res. 2002;19:1446-57.

31. http://www.molinspiration.com

32. http://www.organic-chemistry.org/prog/peo/

33. http://www.organic-chemistry.org/prog/peo/druglikeness.html

34. http://www.organic-chemistry.org/prog/peo/drugScore.html

35. http://www.organic-chemistry.org/prog/peo/tox. html 